\title{
A FILOSOFIA COMO MODO DE VIDA EM FOUCAULT ${ }^{1}$
}

\author{
Thiago Canonenco Naldinho* \\ Hélio Rebello Cardoso Jr.**
}

\begin{abstract}
RESUMO
$\mathrm{O}$ artigo desenvolve a tese de que no cerne da estratégia foucaultiana de enfrentamento à sujeição imposta pelo biopoder - caracterizada pela possibilidade de reabilitação da estética da existência na atualidade -situa-se a prática constante da filosofia. Para tanto, descreve como Foucault entende que a consideração fundamental, similar àquela presente entre os antigos greco-helenístico-romanos, da filosofia como um amálgama constituído por um discurso teórico e seu imprescindível modo de vida respectivo, envolve diretamente a ética com a política e noções relacionadas, como poder, liberdade, autonomia e crítica. Isso posto, o texto define, a partir da conexão de pontos dispersos pela obra de Foucault, qual seria o trabalho específico da filosofia em uma estética da existência, como também descreve o modo de vida respectivo que a filosofia foucaultiana buscava construir, ou seja, a amizade.
\end{abstract}

Palavras-chave: Foucault. Filosofia. Estética da existência. Ética. Amizade.

\begin{abstract}
The article develop the thesis of that in core of the foucaultian strategy - characterized for the possibility of rehabilitation of the aesthetic of the existence in the present time - of confrontation to the subjection imposed for the biopower it is placed the constant practice of the philosophy. For in such a way, it describes as Foucault understands that the basic consideration, similar to that present between the ancient greek-hellenistic-
\end{abstract}

\footnotetext{
* Doutorando em Filosofia pela Universidade Federal de São Carlos (UFSCAR). E-mail: thiago@kanonenko.com.br

** Doutor em Filosofia pela Universidade Estadual de Campinas (UNICAMP). Professor de Filosofia da Universidade Estadual Paulista (UNESP). Livre docente em Filosofia pela Universidade Estadual Paulista (UNESP).E-mail: herebell@hotmail.com
}

1 Agradecemos ao apoio proporcionado pela FAPESP para a realização das pesquisas que serviram de base ao presente trabalho. 
romans, of the philosophy as an amalgam consisting of a theoretical speech and its essential and respective way of life, directly involves the ethics with the politics and related concepts, as well as power, freedom, autonomy and critique. Thereafter, the text define which would be the specific task of the philosophy in an aesthetic of the existence, as well as describe the respective way of life that the foucaultian philosophy implicate, that is, the friendship.

Keywords: Foucault. Philosophy. Esthetics of existence. Ethics. Friendship.

É na morte que me darei conta do progresso moral que terei podido fazer [...]. Espero o dia em que serei juiz de mim mesmo e saberei se minha virtude está nos lábios ou no coração (SÊNECA apud FOUCAULT, 2004a, p. 612).

\section{Introdução}

Se realizarmos um breve panorama da obra de Foucault, considerando-a constituída por três grandes eixos de pesquisa desenvolvidos entre os anos 1960 e 1980, podemos afirmar que a mesma se inicia com os estudos acerca do saber, passando, em um segundo momento, ao tema do poder e, consequentemente, às íntimas e recíprocas relações que esses desenvolvem entre si, as quais Foucault definiu sob o conceito de saber-poder. Mais adiante, em continuidade a tais temáticas, as pesquisas foucaultianas enveredaram-se pelo âmbito da sexualidade com o objetivo de estudá-la enquanto experiência - a correlação, numa cultura, entre campos de saber, tipos de normatividade e formas de subjetividade - a partir do século XVIII. Todavia, Foucault (1984) percebe que este último projeto deveria necessariamente ser re-orientado, ao descobrir que para realizálo necessitaria empreender antes uma genealogia do desejo e do sujeito desejante que passaria pelo cristianismo até a Antiguidade - devido ao fato do tema do desejo estar no centro tanto da teoria clássica da sexualidade quanto daquelas divergentes desta, além de ter sido, aparentemente, herdado, durante os séculos XIX e XX, de uma longa tradição cristã. 
É no contato com os textos greco-helenísticos-romanos que Foucault encontra grande parte das bases para o desenvolvimento de sua terceira e última abrangente dimensão de pesquisas - o $s i$, os processos de subjetivação. Trata-se da constatação de que concomitantemente ao código moral, havia na Antiguidade uma outra modalidade de manifestação moral sob a forma de práticas de si refletidas e voluntárias exercidas pelo indivíduo com o intuito de modificar o seu próprio ser. Havia uma maior preocupação em constituir-se voluntariamente como sujeito moral, realizada por meio dessas práticas éticas, baseadas em critérios de estética e estilo, do que em desenvolver e seguir um restritivo código moral enfim, havia a predominância de uma estética da existência em detrimento da imposição de uma subjetivação codificada. Foucault $(1995,2004)$ nota que a Antiguidade, ao contrário do que até então era equivocadamente relacionado a tal período, mostra-se como uma época de forte austeridade moral sem ter, por isso, a ênfase desta direcionada às exigências de um código, mas antes a um conjunto de práticas de si disponíveis na cultura e na sociedade, as quais eram escolhidas pelos indivíduos que quisessem desenvolver uma ascese, um trabalho de si sobre si com a finalidade de elaborar sua própria vida como uma obra de arte, um estilo, o qual manifestasse os raros e desejados atributos de uma bela existência: justiça, coragem, temperança e prudência.

Se, durante os volumes II e III de sua História da Sexualidade, Foucault havia até então trabalhado a temática da prática de si no campo específico dos aphrodisia - ou seja, na dinâmica constituída pelos atos, prazeres e desejos relacionados à atividade sexual - passa, entretanto, a desenvolver no curso A Hermenêutica do Sujeito o estudo da prática de si em sua íntima relação com a verdade, desta vez independente ou generalizada de qualquer prática ou domínio específico. E é aqui que surgem questões: Qual terá sido a razão de tal re-direcionamento quanto ao tema da prática de si? Se Foucault já havia realizado sua genealogia do sujeito desejante e, por isso, descoberto que durante toda a Antiguidade grecohelenística-romana ainda não havia o predomínio do desejo no campo que envolvia o comportamento sexual e as atividades relacionadas a este, mas antes a presença da dinâmica dos aphrodisia, qual terá sido o motivo que o impulsionou ao prolongamento de suas pesquisas acerca da prática de si 
antiga? Terá sido pelo fato de vislumbrar na ética, no trabalho sobre si, uma saída para o beco em que se viu encurralado devido às suas considerações sobre a sujeição imposta pelos complexos de saber-poder? Teria Foucault visto nas práticas de si uma possibilidade de transformar a economia das relações de poder atuante em nossas sociedades? Para nos aproximarmos da solução dessas questões, é necessário inicialmente compreendermos a maneira como tal pensador entendia os agenciamentos que compõem as sociedades em que vivemos.

De acordo com Foucault (1995a, 2004), desde o século XVI vivemos em sociedades sob uma forma política de poder denominada Estado - desenvolvida devido ao surgimento de uma nova racionalidade política intitulada razão de estado - que empobrece o tecido relacional e afetivo com o intuito de facilitar a administração do recurso constituído pela população. Essa forma de poder político caracteriza-se pelo fato de - diferentemente do poder soberano que tinha na morte o ápice da demonstração de sua força - direcionar seus esforços à proteção e proliferação da vida, uma vez que a considera um recurso indispensável à manutenção, consolidação e expansão de seu campo de ação. Para tanto, esse biopoder utiliza diversos procedimentos que possibilitam-no exercer sobre as pessoas, simultaneamente, processos de individualização e totalização com fins de controle e gerência. Com efeito, como primeira forma desse biopoder, surgem no final do século XVII e início do século XVIII efetivas técnicas de adestramento com o objetivo de aumentar constantemente a utilidade e docilidade dos corpos - as disciplinas; já algumas décadas mais tarde, por volta da metade do século XVIII, inicia-se o exercício de medidas de regulamentação que tem por finalidade dirigir os grandes processos relativos à população, como natalidade, migração, etc. - um polo de intervenção por meio do indivíduo e outro via população que se complementam nas tramas do biopoder. Desse modo, segundo Foucault (1995a), estaríamos sob o jugo de um governo da individualização que, através dos mecanismos e procedimentos característicos do biopoder, produz indivíduos normalizados e reprodutores da norma.

Entretanto, contra essa forma de sujeição, Foucault sugere uma saída - a "recusa deste tipo de individualidade que nos foi imposta há vários séculos" (FOUCAULT, 1995a, p. 239), seguida da intensificação da 
imaginação e criação de novos modos de vida - que parece insinuar uma oportunidade histórica de reabilitação da estética da existência na atualidade. De fato, Foucault relatou sua surpresa acerca da similaridade entre os problemas contemporâneos e os da Antiguidade, o que lhe permitiu pensar que na atualidade os indivíduos, por meio de um intenso trabalho sobre si mesmos, poderiam modelar novos modos de vida que pudessem não apenas resistir, mas também, talvez, escapar à sujeição imposta pelo poder subjetivante moderno. Nossa tese é que dentro da dinâmica onde poderia se efetivar a estilística da existência hoje em dia há, assim como na Antiguidade greco-helenística-romana, um papel de destaque quanto à filosofia, na medida em que esta permearia ou, de certa maneira, englobaria um grande número de práticas de si que o indivíduo utilizaria no processo de sua autoelaboração.

\section{Poder, liberdade, ética e amizade}

Contudo, como a filosofia atuaria especificamente nesse processo de autonomização do sujeito em relação ao atual regime de verdade? O início do percurso para a resposta encontra-se em um texto menor de Kant, de 1784, que visa solucionar a questão proposta por um jornal: "O que é a Aufklärung?". Foucault considera esse texto um marco na filosofia moderna ocidental, porém não devido à conclusão kantiana de que o uso crítico da razão seja a natureza universal da razão, mas antes ao surgimento, de certo modo paralelo, de uma nova problematização: $O$ que é a atualidade? "A reflexão sobre 'a atualidade' como diferença na história e como motivo para uma tarefa filosófica particular me parece ser a novidade desse texto" (FOUCAULT, 2005, p. 341). Ao se perguntar: o que somos nós?; O que caracteriza este momento específico em que vivemos?; Kant estava problematizando, pela primeira vez na filosofia, a historicidade da razão, porém ainda há mais. Segundo Foucault (1984b, 2005), esse questionamento kantiano sobre a atualidade seria o ponto fundamental de uma nova maneira de filosofar que tem como cerne a interrogação crítica acerca do campo de experiências possíveis constituído pela atualidade, isto é, uma ontologia da atualidade e de nós mesmos.

Para Foucault, esse opúsculo kantiano seria o esboço daquilo que viria a se desenvolver como o modo de filosofia característico da 
modernidade - a união de um pensamento crítico acerca da atualidade com a incorporação de seus efeitos -, compreendendo-a não simplesmente como um período histórico, mas, prioritariamente, como uma atitude.

Por atitude, quero dizer um modo de relação que concerne à atualidade; uma escolha voluntária que é feita por alguns; enfim, uma maneira de pensar e de sentir, uma maneira também de agir e de se conduzir que, tudo ao mesmo tempo, marca uma pertinência e se apresenta como uma tarefa. Um pouco, sem dúvida, como aquilo que os gregos chamavam de êthos (FOUCAULT, 2005, p. 341-342, grifo do autor).

Trata-se, evidentemente, de uma concepção de filosofia similar àquela praticada na Antiguidade greco-helenística-romana, ou seja, a filosofia não apenas como discurso filosófico mas também como prática de si, modo de vida. Para Baudelaire - um dos indivíduos mais modernos, de acordo com Foucault - "a atitude voluntária de modernidade está ligada a um ascetismo indispensável. Ser moderno não é aceitar a si mesmo tal como se é no fluxo dos momentos que passam" (FOUCAULT, 2005, p. 344), mas, ao contrário, depende de um exercício de extrema atenção para com o real associado a uma intensa atividade de autoelaboração de si como obra de arte.

Foucault $(2004,2005)$ declarou ser herdeiro dessa vertente filosófica crítica da atualidade que surge com Kant, todavia ressalta que seu fio de ligação a essa não deve ser procurado nos elementos da doutrina dessa tradição, porém, antes, na reativação permanente de seu êthos filosófico. Um modo de ser que traz consigo uma crítica direcionada não mais, como em Kant, à definição dos limites que o conhecimento deve renunciar transpor, mas sim à análise do que pensamos, dizemos e fazemos por meio de uma ontologia histórica de nós mesmos. Essa forma de crítica seria totalmente compatível com a mais urgente tarefa da filosofia na atualidade: "a questão do tempo presente e daquilo que somos neste exato momento" (FOUCAULT, 1995a, p. 239). Temos que estudar os discursos e acontecimentos históricos que determinam aquilo que somos hoje e, simultaneamente, inventar e testar a viabilidade de possibilidades de transposição desses limites. Há, por isso, nessa forma de filosofia um 
intenso comprometimento entre teoria e prática, na medida em que a crítica de nosso ser histórico é diretamente relacionada a nós enquanto sujeitos éticos. Do mesmo modo, para que se consiga definir por aproximações, a filosofia de Foucault não há como evitar invadir ou ser invadido por sua postura de intelectual com suas implicações ético-políticas. Para ele, a figura do intelectual universal portador da verdade e guia das massas deve ser substituída por uma forma de intelectual específico engajado em questões e lutas locais. Essa posição de Foucault decorre diretamente de suas concepções de poder e liberdade, pois o autor não acreditava que estivéssemos alienados de alguma essência ou natureza dos seres humanos devido a procedimentos repressivos do Poder.

No lugar da tradicional concepção de poder que o identificava necessariamente à repressão, Foucault propõe - em $A$ vontade de saber uma concepção positiva, plural e dinâmica de poder. Não haveria o Poder, entendido como um núcleo de inteligibilidade que teria braços intervindo na sociedade, mas sim múltiplas relações de poder traçadas por estratégias anônimas. A repressão seria apenas uma das formas de exercício do poder e, por sinal, não muito sofisticada devido a sua fácil detecção por aqueles que subjuga. Diferentemente do poder soberano que se exercia por meio de sua notória força explícita, o biopoder tem por meta uma modalidade de exercício quase imperceptível, daí vem a sua eficácia. É deveras mais interessante ao biopoder que os indivíduos desejem docilmente estarem de acordo com seus objetivos do que obrigá-los a tanto. Como exemplo, tomemos o sexo e todo um campo de interrogações a este relacionado que envolve importantes questões como liberdade, verdade e poder. Segundo Foucault (1988), toda a problematização ao redor do sexo, surgida no século XVIII - a qual inventa a sexualidade como chave de compreensão, autonomização e aperfeiçoamento ético-político do sujeito, contrariamente ao que aparenta-, situa-se de acordo com uma ardilosa estratégia do biopoder. Enquanto os movimentos de luta por liberação sexual e reconhecimento de direitos relacionados nos séculos XX e XXI ainda acreditam enfrentar as arbitrariedades de um poder conservador e proibitivo, na realidade coadunam e promovem os processos de individualização que ligam coercivamente o indivíduo a uma identidade, no caso sexual, apoiados em uma secular técnica de confissão que busca no sujeito sua verdade íntima. 
Enfim, a liberdade não seria algo que deveríamos lutar para reconquistar, mas, antes, aquilo que exercemos quotidianamente. Por isso, dever-seia trocar o foco da atenção das práticas de liberação para as práticas de liberdade - o que podemos realizar enquanto sujeitos livres que somos?

Dessa maneira, as lutas contra o biopoder não teriam por objetivo a conquista de uma suposta liberdade outrora usurpada, mas sim, primeiramente, a recusa, por meio do exercício de nossa liberdade, daquele tipo de individualidade que nos é imposto. As pessoas já alcançaram a "idade da maioridade política e moral. Cabe a elas escolher individualmente, coletivamente" (FOUCAULT apud ADORNO, 2004, p. 45). O intelectual pode, através de suas análises, esclarecer o modo de funcionamento da política de verdade ou da economia das relações de poder atuantes em uma sociedade, entretanto a escolha e a ação dependem diretamente de cada indivíduo. Há, com isso, a atribuição às pessoas da responsabilidade pela mudança social, uma vez que o modo como cada uma pensa e age influencia os rumos de toda a sociedade: há na filosofia prática de Foucault uma ligação direta entre ética e política. Torna-se, agora, mais evidente o motivo da rejeição por Foucault da postura do intelectual profeta de verdades que dirige a população em direção à revolução. Ao constatar empiricamente os repetidos fracassos de todas as promessas e hipóteses revolucionárias durante os últimos séculos, Foucault aposta que as lutas contra o governo da individualização não devem seguir qualquer programa, mas sim atuar no enfrentamento local dos mecanismos de poder. Em vez de uma grande luta revolucionária nos moldes da crítica esquerdista, acredita na irrupção de múltiplos focos de resistência anárquicos e imediatos: sublevações ou revoltas reais no lugar de revoluções esquematizadas vazias.

Contudo, a filosofia que Foucault desenvolve não é ética apenas por encarregar cada indivíduo da responsabilidade pelas mudanças quanto à economia das relações de poder ou à política. Assim como Baudelaire defendia a indispensabilidade de um ascetismo ao sujeito que quisesse constituir-se como moderno, Foucault ressalta a importância da transformação do sujeito por si próprio. Além do ativo trabalho de atenção para com a atualidade que busca diagnosticar os limites que determinam o que somos, há também na ontologia do presente uma intensa atitude experimental ou ensaística que busca inventar a forma daquilo que 
seremos ao ultrapassar tais fronteiras e, assim, preencher positivamente a liberdade que exercemos. Trata-se de uma crítica prática na medida em que questiona aquilo em nós encarnado e situa-se como prova históricoprática dos limites que podemos transpor por meio desse trabalho sobre nós mesmos. Uma filosofia extremamente ética, na medida em que Foucault (2004) considera a ética como a prática refletida da liberdade. "Em suma, trata-se, para Foucault, de fazer da ética, e não da elaboração teórica em si mesma, a pedra de toque da prática filosófica" (ADORNO, 2004, p. 56). Como afirma Hadot (2004), referindo-se aos antigos greco-helenísticoromanos, um discurso somente é filosófico enquanto implicar um modo de vida.

Foucault nos forneceu algumas pistas a respeito dos princípios que permeariam a filosofia por ele praticada, bem como acerca do modo de vida que gostaria de alcançar através dessa ascese crítica e criativa. Como diagnosticador do presente, ao analisar as racionalidades atuantes em nossas sociedades, Foucault preocupava-se não apenas com os abusos que o poder político moderno inflige às pessoas por meio do regime de saber, mas também com a conduta dos indivíduos no exercício de seus poderes sobre os outros. O problema não seria as relações de poder enquanto jogos estratégicos entre liberdades constantemente mutantes e reversíveis que se estabelecem provisoriamente entre os indivíduos, mas os estados de dominação - relações solidificadas que impossibilitam a mobilidade e inversão das forças em jogo. Acerca disso, Foucault acredita que é na participação nos jogos de poder com o mínimo de dominação que está o ponto de junção entre a "preocupação ética e a luta política pelo respeito dos direitos, entre a reflexão crítica contra as técnicas abusivas de governo e a investigação ética que permite instituir a liberdade individual" (FOUCAULT, 2004, p. 285). Para tanto, é necessário agir de maneira extremamente prudente - atento a todos os detalhes - e empírica - guiada por um princípio crítico que avalie a necessidade, para a estratégia em questão, da presença de possíveis focos de não consensualidade - pois a linha de demarcação entre jogos estratégicos em liberdade e estados de dominação é difusa e de difícil definição.

Essa postura ética de busca, identificação e exclusão de focos de dominação na conduta individual parece ser relacionada por Foucault 
(1981) àquilo que o mesmo define por amizade - um modo de vida que busca constantemente tornar-se mais suscetível, como também mais preocupado com o outro, no campo dos prazeres. Um modo de relação que não apenas possui, propositadamente, forma indefinida, mas também cultiva a irrupção e a interação com a diferença. Assim, mais uma vez, evidencia-se na filosofia foucaultiana uma intensa ligação recíproca entre ética e política, pois a amizade situa-se tanto como uma escolha pessoal que define a forma do sujeito que a vive, quanto uma posição e ação política. Não se trata somente de evitar infligir dominação a outro indivíduo, pois nela também há um efeito macropolítico - uma vez que Foucault (1981) acreditava que a partir de um modo de vida pode surgir uma cultura.

Aqui as peças do quebra-cabeça, constituído pela estratégia foucaultiana de enfrentamento ao poder político moderno, organizamse de modo a formar figuras mais compreensíveis. Com efeito, o modo de vida entendido por Foucault como amizade é a materialização em comportamentos e ações dos princípios defendidos por sua filosofia: a amizade é a filosofia foucaultiana enquanto modo de vida ${ }^{2}$. Assim, o indivíduo que vive a amizade poderia tanto desenvolver um processo de desassujeitamento em relação ao biopoder, quanto à propagação, por meio da materialização em si, da verdade relativa à filosofia da amizade; suas ações trazem em si uma verdade indissociável que exerce indistintamente seus efeitos sob a forma de poder. A existência, com todas as indispensáveis escolhas que lhe batem à porta, é inerentemente um ato político.

\footnotetext{
2 Convém ressaltar que não estamos afirmando com isso que todos os processos de subjetivação influenciados pelo discurso foucaultiano tenham como forma resultante o modo de vida da amizade. Mas antes que, devido ao modo como Foucault compreendia a filosofia - extremamente semelhante à maneira como a filosofia fora experenciada pelos antigos greco-helenístico-romanos: um amálgama constituído por um discurso e modo de vida necessariamente correspondentes e harmoniosos - acreditamos que suas ideias e seu discurso filosóficos foram vivenciados por ele próprio de maneira intensa e marcante em um específico modo de vida sob permanente construção - a amizade (CARDOSO JR.; NALDINHO, 2009). Contudo, a partir de uma tal concepção de filosofia, seria também legítimo supor que indivíduos que tivessem os princípios e enunciados da filosofia de Foucault "encarnados" em seus atos teriam, por isso, a amizade por modo de vida (FOUCAULT, 2004a, 2006; HADOT, 2004).
} 


\section{Governabilidade e autonomia}

Desse modo, a filosofia enquanto crítica histórico-prática dos limites que determinam aquilo que somos estaria em meio a uma dinâmica com a ética e a política, com o indivíduo e a cultura. Seu objetivo não seria mais prevenir - o que vem tentando realizar, sem muito sucesso desde Kant - os abusos de poder da razão, porém antes analisar as racionalidades específicas que constituem nossa racionalidade política, para assim compreender o nexo de saber-poder que a sustentam e identificar suas específicas linhas de ruptura ou ultrapassagem em direção a uma nova economia das relações de poder ou política da verdade.

Sendo a racionalidade política a matriz de um grande número de postulados, de evidências de vários tipos, de instituições e de idéias que consideramos adquiridas, é duplamente importante, de um ponto de vista teórico e prático, prosseguir essa crítica histórica, essa análise histórica de nossa racionalidade política, que é um pouco diferente das discussões referentes às teorias políticas, mas também das divergências de escolhas políticas (FOUCAULT, 2004, p. 316-317).

Seria através da análise e transformação de nosso modo de pensar político - racionalidade política - que alteraríamos tanto a forma do poder político a que nos submetemos, quanto, consequentemente, a modalidade de exercício de poder daquele sobre nós. Como uma pista, poder-se-ia seguir a impressão de Foucault acerca da maneira como o sujeito é, talvez desde Rousseau e Hobbes, pensado politicamente - essencialmente como "sujeito de direito, quer em termos naturalistas, quer em termos do direito positivo" (FOUCAULT, 2004, p. 279) - à qual contrapõe a noção de governabilidade 3 que leva em conta a matéria da ética, ou seja, a liberdade

\footnotetext{
3 Mesmo considerando parcialmente apropriada a distinção que Veiga-Neto (1996) realiza entre os termos governabilidade e governamentalidade - os quais, segundo o autor, são frequentemente confundidos devido à tradução equivocada de gouvernementalité - não estamos tão certos em relação a tal diferenciação, pois encontramos em $A$ hermenêutica do Sujeito (FOUCAULT, 2001, p. 241, 2004a, p. 306), tanto na edição brasileira quanto na francesa, uma definição de governamentalidade (gouvernementalité) deveras semelhante àquilo que Foucault (2004, p. 287) entende por governabilidade. De modo que, devido a esse
} 
do sujeito e sua relação com os outros. Dever-se-ia, paradoxalmente, não mais lutar apenas por direitos, mas, antes, por um novo direito - um direito relacional que permitisse a possibilidade de existência de todas as formas possíveis de relações e impedisse que estas fossem bloqueadas ou empobrecidas por instituições.

Todavia, para que tal filosofia crítica se exerça, é indispensável uma condição anterior que Foucault relata ter demorado a isolar, mesmo tendo esbarrado com ela em suas pesquisas anteriores. Com efeito, a crítica, ao contrário de configurar-se apenas como uma especulação teórica, seria algo mais próximo de uma atitude, ao mesmo tempo individual e coletiva, caracterizada por uma intensa vontade de mudança quanto à forma que se é governado. A crítica seria uma atitude de questionamento e recusa em relação a uma forma política de poder considerada como inadequada. Um ato de coragem que brota de uma vontade de mudança em relação aos jogos de saber-poder. Um processo através do qual o sujeito autolegitima seu direito ao questionamento da verdade sobre seus efeitos de poder e do poder acerca de seus discursos de verdade; em suma "a crítica será a arte da inservidão voluntária, aquela da indocilidade refletida [...] teria essencialmente por função o desassujeitamento no jogo do que se poderia chamar, em uma palavra, a política da verdade" (FOUCAULT, 1990).

Contudo, cabem aqui algumas considerações a respeito dessa crítica contra as formas de sujeição política. Para Kant e a tradição da Aufklärung que chega até a Escola de Frankfurt, a crítica, diferentemente daquilo que Foucault afirma, teria como maior objetivo a análise da razão, ou de um tipo específico de razão - "idéia que nós fazemos do nosso conhecimento e dos seus limites” (FOUCAULT, 1995a, p. 233). A obediência a uma instância organizada de poder político não constituía um problema fundamental para Kant, uma vez que o mesmo acreditava que o processo para alcançar a autonomia ou estado de maioridade não passava necessariamente pela recusa de qualquer forma de governo, mas antes pelo

e outros motivos que não cabem ser esmiuçados nesta nota, preferimos compreender a noção de governabilidade no seu sentido mais geral, independente da variável "Estado", como a qualidade daquilo que é governável, ou seja, o que denomina o jogo de forças e estratégias atuantes nas relações de poder que visam o governo da conduta, ou a determinação do campo de possibilidades, de outros agentes livres (FOUCAULT, 1995a, p. 242-245). 
uso da razão universal, livre e pública. O que não significa que Kant não se preocupava com a questão dos abusos de poder da razão, mas sim que via nesse uso específico da razão a possibilidade de fundamentar os princípios de um possível governo que se comprometesse com a manutenção de um suposto estado de maioridade alcançável pela sociedade. E quanto a Foucault? Quais seriam suas considerações a respeito da autonomia? Bem, pode-se seguir pelo menos dois raciocínios em relação as suas opiniões sobre o tema. Por um lado, seria coerente deduzir que Foucault acredita em um estado de maioridade a ser atingido pelo homem, uma vez que afirmou fazer parte da vertente filosófica crítica da atualidade que tem suas raízes na Aufklärung e "problematiza simultaneamente a relação com o presente, o modo de ser histórico e a constituição de si próprio como sujeito autônomo" (FOUCAULT, 2005, p. 344-345, grifo nosso). Em compensação, em outras ocasiões, Foucault $(1990 ; 2005)$ declara não estar tão certo nem quanto à possibilidade de efetivação da autonomia nem quanto ao anseio dos indivíduos por tal estado. Com efeito, o pensador compreendia a ideia de um anarquismo fundamental - algo como uma liberdade selvagem à toda governamentalização - como o paroxismo filosófico e teórico da vontade de não ser relativamente governado que se mostra viva e presente na crítica.

Desse modo, após considerar essas digressões conceituais, podese deduzir que no pensamento foucaultiano a autonomia não depende, assim como em Kant, de uma completa e extrema recusa a qualquer forma de governo. Na medida em que Foucault não crê na ideia de uma liberdade originária que tenha sido expropriada do homem por mecanismos repressivos do poder, parece que o estado de maioridade, entendido por tal autor, refere-se a alguma dimensão além, ou até aquém, da liberdade. De modo semelhante à maneira como compreende a noção de poder - que só existe em ato, como ações sobre ações dentro de um campo de possibilidades com o intuito de conduzir as condutas de sujeitos atuantes -, a autonomia aparenta ser trabalhada por Foucault como algo necessariamente em movimento, em prática. Não se trataria de uma meta distante, estável e perene a ser possivelmente alcançada, porém de breves lampejos de exercício da crítica, a autonomia seria essencialmente algo fugidio que não podemos possuir, mas apenas perseguir constantemente sua 
prática. Contudo, independentemente do modo e da duração desse estado de maioridade, como seria exequível atingi-lo? Uma possibilidade seria pensar que por meio da relação consigo, da ascese, o indivíduo pudesse exercer um estado de autogoverno que lhe permitisse a constituição de si por si próprio como um sujeito que desfrute da autonomia e, consequentemente, desenvolver relações interindividuais baseadas nessa experiência de maioridade. Sob essa perspectiva, a filosofia teria grande importância, uma vez que a concepção foucaultiana dessa assemelha-se àquela praticada na Antiguidade greco-helenística-romana, a qual era considerada como "o conjunto de princípios e práticas que se pode ter à própria disposição ou colocar à disposição dos outros, para tomar cuidados, como convém, de si mesmo ou dos outros" (FOUCAULT, 2004a, p. 167).

No entanto, Foucault (2004) adverte-nos constatando a possibilidade de interpretações equivocadas quanto à real importância da relação consigo em todo esse processo de desassujeitamento do si e da sociedade. A prática de si não seria por si só uma garantia de autonomia, pois as técnicas de si não são inventadas em face de um problema, porém, antes se encontram, como dissemos, disponíveis no social e podem, inclusive, não ser necessariamente voluntárias, mas até mesmo obrigatórias.

Não acredito que o único ponto de resistência possível ao poder político - entendido justamente como estado de dominação - esteja na relação de si consigo mesmo. Digo que a governabilidade implica a relação de si consigo mesmo, o que significa justamente que, nessa noção de governabilidade, viso ao conjunto das práticas pelas quais é possível constituir, definir, organizar, instrumentalizar as estratégias que os indivíduos, em sua liberdade, podem ter uns em relação aos outros (FOUCAULT, 2004, p. 287, grifo nosso).

Em adição a isso, pode-se considerar o que Foucault (2004) diz, um pouco antes durante a mesma entrevista, a respeito dos efeitos coercitivos da verdade sobre a sociedade e do caráter dominador não essencial às relações de poder. Com efeito, segundo o autor, a questão fundamental não estaria na tentativa de dissolver tais relações na utopia de uma comunicação perfeitamente transparente, porém, sim, na utilização de 
"regras de direito, técnicas de gestão e também a moral, o êthos, a prática de si, que permitirão, nesses jogos de poder, jogar com o mínimo possível de dominação" (FOUCAULT, 2004, p. 284-285, grifo do autor). Por tudo isso, é possível perceber que Foucault, quando se questionava acerca de uma nova economia das relações de poder para nossas sociedades, não tinha em mente uma comunidade utópica onde não houvesse leis ou normas a que os indivíduos - esclarecidos e imunes de qualquer modalidade de sujeição por um regime de saber-poder - fossem obrigados a se submeter. A grande questão sobre tudo isso estaria no modo como tanto a prática de si, quanto as regras de direito e as técnicas racionais de governo seriam pensadas, ou seja, na racionalidade que as sustentaria, por isso a necessidade da análise.

\section{Problematização e filosofia}

Nessa empreitada filosófica sobre nós mesmos - por meio de uma extrema e permanente crítica dos limites que determinam o que somos, aliada a uma intensa atitude experimental de buscar moldar a forma daquilo que estava outrora contido em tais fronteiras - a matéria a ser trabalhada é o pensamento. Entendido não como o conjunto de representações que fundamentam, nem tampouco como o domínio de atitudes que determinam certo comportamento, mas sim como aquilo que nos permite tomar um campo de ação como objeto de questionamento quanto a seu significado, condições e objetivos. "O pensamento é a liberdade com relação ao que se faz, o movimento pelo qual se toma distância desse fazer, constituindo-o como objeto e refletindo sobre ele como problema" (FOUCAULT 1999a, p. 24). De fato, deve-se considerar a problematização como o trabalho específico do pensamento, isto é:

o conjunto das práticas discursivas ou não discursivas que faz alguma coisa entrar no jogo do verdadeiro e do falso e a constitui como objeto para o pensamento (seja sob a forma de reflexão moral, do conhecimento científico, da análise política, etc.) (FOUCAULT, 1984a, p. 76). 
É através do trabalho característico do pensamento que algo se constitui como um problema a ser refletido e solucionado-a problematização seria o exercício da liberdade enquanto questionamento dos fatos e evidências em busca da mudança de algo situado como dificuldade. Sobre isso, quanto ao presente, Foucault discorda da vertente que define a nossa época com um grande vazio estéril e decadente de pensamento. Para o pensador, pelo contrário, há um sentimento de "nenhum lugar vazio" (FOUCAULT, 1980) devido à abundância de produção, sufocada pela escassez de canais que permitam às pessoas expressar e ouvir conhecimento, o que desenvolve uma angústia manifestada em sintomas - entre eles, essa sensação de época decadente e sombria - porém, contudo, Foucault não aceita a ideia de que tudo vai mal. Se "é o conhecimento que estimula o pensamento" (FOUCAULT, 2006, p. 315-316), uma urgente tarefa seria a ampliação e desenvolvimento de canais de comunicação, uma vez que a curiosidade, o desejo de saber, já está presente nas pessoas - tratar-se-ia da materialização daquilo que Foucault (1980) sonhava e denominava idade da curiosidade.

Todavia, a maneira como as pessoas pensam é, inevitavelmente, influenciada por uma tradição de racionalidade constituída por componentes da economia, política, ciência, história, sociedade, etc. Como, então, poderia um sujeito questionar os abusos do poder político se se encontraria limitado a um modo de pensar sustentado por uma tradição de racionalidade política? A solução estaria em pensar de modo diverso do habitual, pois apenas quando isso ocorresse seria exequível o diagnóstico de obstáculos outrora desconhecidos. No entanto, haveria a possibilidade de expandir os horizontes de percepção e reflexão do pensamento? Foucault aponta que a resposta para essa ousada questão encontrar-se-ia na filosofia, uma vez que, como mencionado acima, esta teria como material e instrumento de trabalho o pensamento. Sobre isso, o autor nos questiona: "o que é filosofar hoje em dia - quero dizer, a atividade filosófica - senão o trabalho crítico do pensamento sobre o próprio pensamento?" (FOUCAULT, 1984, p. 13). Pois bem, e o que seria isso a não ser a consideração da filosofia como uma dobra do pensamento sobre o pensamento? 
A filosofia é o movimento pelo qual nos libertamos - com esforços, hesitações, sonhos e ilusões - daquilo que passa por verdadeiro, a fim de buscar outras regras do jogo. A filosofia é o deslocamento e a transformação das molduras de pensamento, a modificação dos valores estabelecidos, e todo o trabalho que se faz para pensar diferentemente, para fazer diversamente, para tornar-se outro do que se é (FOUCAULT, 1980, grifo nosso).

Se a problematização, como sabemos, é o trabalho específico do pensamento, poder-se-ia dizer que a filosofia é a problematização do ato de problematizar; a tomada do ato de pensar como objeto de um problema a ser refletido, trabalhado e ultrapassado; a atividade que analisa criticamente o pensamento e, com a diferença, ensaia a mudança.

Como vimos, a filosofia em Foucault não se situa apenas como um discurso teórico acerca da realidade, ao contrário, mantém com a prática uma dinâmica de sustentação recíproca. Desse modo, seu trabalho específico interfere diretamente na maneira como os indivíduos e a sociedade pensam e, por isso, nos caminhos da ação política. "Há pouco dizia que a filosofia é um modo de refletir sobre a nossa relação com a verdade. É preciso acrescentar: é um modo de perguntar-se: se esta é a relação que temos com a verdade, como devemos comportar-nos?" (FOUCAULT, 1980, grifo nosso). Seria a maneira como o indivíduo se relaciona com a verdade e suas consequentes escolhas que determinariam seu modo de vida. Como sugere Deleuze (1992), ao dizermos e fazermos algo, deveríamos nos questionar a respeito do modo de existência que tais palavras e atos acarretam. Entretanto, além dessa implicação ética e direta entre a relação que o indivíduo mantém com a verdade e a maneira como este se comporta, há um outro lado interessante da mesma questão; seria através de seus atos que um indivíduo poderia atestar as verdades que professa e/ ou diz seguir. Acerca disso, Foucault (2006) destacou em várias ocasiões a necessidade da consonância entre as palavras e os atos no exercício da função do intelectual, contrapondo-a à figura do intelectual universal. Para tal pensador, a chave da atitude política pessoal de um filósofo deveria ser buscada em seu êthos, em sua filosofia como modo de vida, e não em suas ideias. Dessa forma, evidencia-se em Foucault um modo de relação com a 
verdade que busca, assim como entre os antigos estóicos, a constituição de si como sujeito ético da verdade ou sujeito da ação reta - a verdade que se tem por princípio ético é constantemente verificada quanto a sua efetividade pela vida enquanto prova ${ }^{4}$. O modo de vida que ele buscava atingir, ou continuar a construir, tinha como prática uma ética do desprendimento de si com o intuito da constante reinvenção de si - "uma elaboração de si para si, uma transformação estudiosa, uma modificação lenta e árdua pelo cuidado constante da verdade" (FOUCAULT, 1984a, p. 82).

\section{Considerações finais}

Após toda essa descrição do que Foucault denomina por filosofia, a partir da questão surgida no pequeno texto de Kant em resposta à pergunta “o que é a Aufklärung?", pudemos compreender alguns pontos. A filosofia foucaultiana seria, assim como aquelas presentes na Antiguidade grecohelenística-romana, um amálgama constituído por um discurso e prática indissociáveis direcionados à elaboração de um modo de vida. Seu êthos, ao contrário daquele almejado pelos antigos, não anseia alcançar um estado de soberania ou tranquilidade da alma, mas antes o incessante desassossego - compreendido, diferentemente do otimismo cético que busca alcançar verdades seguras e irrefutáveis, como um hiperativismo pessimista que não considera tudo ruim, porém procura constantemente determinar o principal perigo a ser combatido, inclusive em si mesmo. Um modo de vida que tem como condição de sua efetivação o exercício de uma permanente atitude crítica de si e da atualidade com o intuito de evitar e recusar a sujeição a efeitos de verdade coercitivos e estados de dominação que se podem impor e sofrer, aliado à meta de se tornar mais suscetível e

\footnotetext{
4 A questão do modo de relação que a filosofia de Foucault mantém com a verdade incita uma discussão teórico-conceitual específica. Com efeito, apesar de não caber nesta nota um comentário mais elaborado argumentativamente, convém relatarmos nossa posição discordante com as ideias de Gros, uma vez que tal autor acredita que Foucault teria alterado a partir do curso $A$ coragem da verdade a maneira como entendia a relação da vida enquanto prática de si com a verdade, a qual desde então estaria mais próxima de uma concepção cínica - caracterizada pela irrupção nua e violenta da verdade na vida, onde a primeira testa a segunda - do que da concepção mais próxima ao estoicismo definida pela ideia de sujeito da ação reta (FOUCAULT, 2004a, GROS, 2004, 2004a, 2004b).
} 
incitador do prazer tanto para si quanto para os outros. Em suma, o êthos ou modo de vida da amizade. Uma modalidade de saber prático e etopoético que não objetiva tornar-se uma teoria unitária, mas antes permanecer, por meio de sua incessante autocrítica, em estado de constante instabilidade criativa, a qual analisa os limites e fornece instrumentos de ultrapassagem no campo da experiência que envolve as relações de força e poder consigo e com os outros, a ética e a política, o autogoverno e a governabilidade. Uma filosofia não destrutiva, porém, ao contrário, positiva, pois, elaborada a partir de "centelhas de imaginação" no trabalho infinito da liberdade (FOUCAULT, 1980).

\section{Referências}

ADORNO, F. P. A tarefa do intelectual: o modelo socrático. In: GROS, F. (Org.). Foucault: a coragem da verdade. São Paulo: Parábola Editorial, 2004. ARTIÈRES, P. Dizer a atualidade: o trabalho de diagnóstico em Michel Foucault. In: GROS, F. (Org.). Foucault: a coragem da verdade. São Paulo: Parábola Editorial, 2004.

BRANCO, G. C. As lutas pela autonomia em Michel Foucault. In: RAGO, M. e ORLANDI, L. B. L.; VEIGA-NETO, A. (Org.). Imagens de Foucault e Deleuze: ressonâncias nietzschianas. Rio de Janeiro: DP\&A, 2005.

BRANCO, G. C. Considerações sobre ética e política. In: BRANCO, G. C.; PORTOCARRERO, V. Retratos de Foucault. Rio de Janeiro: Nau, 2000.

CARDOSO JR., H. R; NALDINHO, T. C. A amizade para Foucault: resistências criativas face ao biopoder. Fractal: Revista de Psicologia, Niterói, v. 21, n. 1, p. 43-56, jan./abr. 2009. Disponível em: $<$ http://www. uff.br/periodicoshumanas/index.php/Fractal/article/view/194/268>. Acesso em: 11 Out. 2010.

DELEUZE, G. A vida como obra de arte. In: . Conversações. Rio de Janeiro: 34, 1992.

; FOUCAULT, M. Un diálogo sobre el poder. In: MOREY, M. (Org.). Un diálogo sobre el poder y outras conversaciones. Madrid: Alianza Editorial, 2001. 
FOUCAULT, M. Le Philosophe masqué. Le Monde, n. 10945, p. 1, 6 avril. 1980. Disponível em: <http://www.unb.br/fe/tef/filoesco/foucault/ mascarado.html>. Acesso em: 10 Nov. 2006.

. De l'amitié comme mode de vie. Gai Pied, 25, p. 38-39, Abr. 1981. Disponível em: <http://www.unb.br/fe/tef/filoesco/foucault/amitie. html>. Acesso em: 10 Nov. 2006.

. Est-il donc important de penser? Libération, n. 15, p. 21, 30-31, Maio. 1981a. Disponível em: <http://www.unb.br/fe/tef/filoesco/foucault/ importantepensar.html>. Acesso em: 10 Nov. 2006.

. História da sexualidade, 2: o uso dos prazeres. Rio de Janeiro: Graal, 1984.

. O cuidado com a verdade. In: ESCOBAR, C. H. (Org.). $M$. Foucault, 1926/1984. O dossier: últimas entrevistas. Rio de Janeiro: Taurus, 1984a.

. O que é o Iluminismo. In: ESCOBAR, C. H. (Org.). M. Foucault, 1926/1984. O dossier: últimas entrevistas. Rio de Janeiro: Taurus, 1984b.

. Sex, power and the politics of identity. The Advocate, p. 26-30, Ago.1984b. Disponível em: <http://www.unb.br/fe/tef/filoesco/foucault/ sexpodident.html>. Acesso em: 10 Nov. 2006.

. Foucault passe-frontières de la philosophie. Le Monde, Set. 1986. Disponível em: <http://www.unb.br/fe/tef/filoesco/foucault/frontieres. html Acesso em: 10 Nov. 2006.

. História da sexualidade, 1: a vontade de saber. Rio de Janeiro: Graal, 1988.

. Qu'est-ce que la critique? critique et Aufklärung. Bulletin de la Société française de philosophie, v. 82, n. 2, p. 35-63, abr./jun. 1990. Disponível em: <http://www.unb.br/fe/tef/filoesco/foucault/critique. html >. Acesso em: 10 Nov. 2006.

. "Omnes et singulatim": vers une critique de la raison politique. In: DEFERT, D.; EWALD, F. Dits et Écrits 1954-1988. Paris, Gallimard, 1994. (Dits et Écrits, v. 4 (1980-1988). Disponível em: <http://www.unb. $\mathrm{br} / \mathrm{fe} / \mathrm{tef} /$ filoesco/foucault/omnesetsingulatim.html $>$. Acesso em: 2 Jan. 2008. 
Michel Foucault entrevistado por Hubert L. Dreyfus e Paul Rabinow. In: RABINOW, P. ; DREYFUS, H. Michel Foucault, uma trajetória filosófica: para além do estruturalismo e da hermenêutica. Rio de Janeiro: Forense Universitária, 1995.

. O sujeito e o poder. In: RABINOW, P. ; DREYFUS, H. Michel Foucault, uma trajetória filosófica: para além do estruturalismo e da hermenêutica. Rio de Janeiro: Forense Universitária, 1995a.

. Em Defesa da Sociedade. Rio de Janeiro: Martins Fontes, 1999.

. Política da Verdade: Paul Rabinow entrevista Michel Foucault. In:

. Antropologia da Razão: ensaios de Paul Rabinow. Rio de Janeiro:

Relume Dumará, 1999a.

. Herméneutique du sujet: Cours au Collège de France, 1981-1982. Paris: Seuil/Gallimard, 2001.

. Ética, sexualidade e política. (Ditos \& Escritos, v. 5). Rio de Janeiro: Forense Universitária, 2004.

. A Hermenêutica do Sujeito. São Paulo, Martins Fontes, 2004a.

. O que são as luzes? In: Arqueologia das ciências e história dos sistemas de pensamento. (Ditos \& Escritos, v. 2). Rio de Janeiro: Forense Universitária, 2005.

. Estratégia, poder-saber. (Ditos \& Escritos, v. 4). Rio de Janeiro: Forense Universitária, 2006.

. Verdade e Poder. In: . Microfísica do Poder. Rio de Janeiro: Graal, 2006b.

GROS, F. A parrhesia em Foucault (1982-1984). In: . (Org.). Foucault: a coragem da verdade. São Paulo: Parábola Editorial, 2004.

. Introdução: A coragem da verdade. In: GROS, F. (Org.). Foucault: a coragem da verdade. São Paulo: Parábola Editorial, 2004a.

. Situação do Curso. In: FOUCAULT, M. A Hermenêutica do Sujeito. São Paulo: Martins Fontes, 2004b.

HADOT, P. O que é a filosofia antiga? São Paulo: Loyola, 2004.

PRADEAU, J. O sujeito antigo de uma ética moderna. In: GROS, F. (Org.). Foucault: a coragem da verdade. São Paulo: Parábola Editorial, 2004. 
RABINOW, P. O que é a maturidade? Habermas e Foucault sobre "O que é o Iluminismo?". In: . Antropologia da Razão: ensaios de Paul Rabinow. Rio de Janeiro: Relume Dumará, 1999.

. Sujeito e governamentalidade: elementos do trabalho de Michel Foucault. In: Antropologia da Razão: ensaios de Paul Rabinow. Rio de Janeiro: Relume Dumará, 1999a.

; DREYFUS, H. Michel Foucault, uma trajetória filosófica: para além do estruturalismo e da hermenêutica. Rio de Janeiro: Forense Universitária, 1995.

RAJCHMAN, J. Foucault: A Liberdade da Filosofia. Rio de Janeiro: Jorge Zahar Editor, 1987.

REVEL, J. O pensamento vertical: uma ética da problematização. In: GROS, F. (Org.). Foucault: a coragem da verdade. São Paulo: Parábola Editorial, 2004.

VEIGA-NETO, A. Governabilidade ou governamentalidade? Disponível em: http://www.ufrgs.br/faced/alfredo/governo1.htm. Acesso em: 7 Jan. 2008.

Data de registro: $12 / 10 / 2010$

Data de aceite: 15/06/2011 